\title{
Coat colour in dogs: identification of the Merle locus in the Australian shepherd breed
}

\author{
Benoit Hédan ${ }^{1}$, Sébastien Corre ${ }^{1}$, Christophe Hitte ${ }^{1}$, Stéphane Dréano ${ }^{1}$, \\ Thierry Vilboux ${ }^{1}$, Thomas Derrien ${ }^{1}$, Bernard Denis ${ }^{2}$, Francis Galibert ${ }^{1}$, Marie- \\ Dominique Galibert ${ }^{1}$ and Catherine André*1
}

\begin{abstract}
Address: ${ }^{1}$ UMR 6061 CNRS, Génétique et Développement, Faculté de Médecine, Université de Rennes1, 35043 RENNES Cédex, France. and 25 avenue Foch 54200 Toul, France.

Email: Benoit Hédan - benoit.hedan@univ-rennes1.fr; Sébastien Corre - sebastien.corre@univ-rennes1.fr; Christophe Hitte - christophe.hitte@univ-rennes1.fr; Stéphane Dréano - stephane.dreano@univ-rennes1.fr; Thierry Vilboux - thierry.vilboux@univ-rennes1.fr; Thomas Derrien - thomas.derrien@univ-rennes1.fr; Bernard Denis - denis.brj@wanadoo.fr; Francis Galibert - francis.galibert@univ-rennes1.fr; Marie-Dominique Galibert - marie-dominique.galibert-anne@univ-rennes1.fr; Catherine André* - catherine.andre@univ-rennes1.fr

* Corresponding author
\end{abstract}

Published: 27 February 2006

BMC Veterinary Research2006, 2:9 doi:10.1/86/1746-6/48-2-9

This article is available from: http://www.biomedcentral.com/I746-6/48/2/9

(c) 2006Hédan et al; licensee BioMed Central Ltd.

This is an Open Access article distributed under the terms of the Creative Commons Attribution License (http://creativecommons.org/licenses/by/2.0), which permits unrestricted use, distribution, and reproduction in any medium, provided the original work is properly cited.
Received: II November 2005

Accepted: 27 February 2006

\begin{abstract}
Background: Coat colours in canines have many natural phenotypic variants. Some of the genes and alleles involved also cause genetic developmental defects, which are also observed in humans and mice. We studied the genetic bases of the merle phenotype in dogs to shed light on the pigmentation mechanisms and to identify genes involved in these complex pathways. The merle phenotype includes a lack of eumelanic pigmentation and developmental defects, hearing impairments and microphthalmia. It is similar to that observed in microphthalmia mouse mutants.
\end{abstract}

Results: Taking advantage of the dog as a powerful genetic model and using recently available genomic resources, we investigated the segregation of the merle phenotype in a five-generation pedigree, comprising 96 sampled Australian shepherd dogs. Genetic linkage analysis allowed us to identify a locus for the merle phenotype, spanning 5.5 megabases, at the centromeric tip of canine chromosome 10 (CFA I0). This locus was supported by a Lod score of 15.65 at a recombination fraction $\theta=0$. Linkage analysis in three other breeds revealed that the same region is linked to the merle phenotype. This region, which is orthologous to human chromosome I2 (HSAl2 ql3-ql4), belongs to a conserved ordered segment in the human and mouse genome and comprises several genes potentially involved in pigmentation and development.

Conclusion: This study has identified the locus for the merle coat colour in dogs to be at the centromeric end of CFAIO. Genetic studies on other breeds segregating the merle phenotype should allow the locus to be defined more accurately with the aim of identifying the gene. This work shows the power of the canine system to search for the genetic bases of mammalian pigmentation and developmental pathways. 


\section{Background}

Coat colours in mammals depend on skin and hair pigment synthesis. Melanocytes manufacture two types of melanin: the black/brown photo-protective eumelanin pigment, and the red-yellow cytotoxic phaeomelanin pigment. Several paracrine factors secreted primarily by surrounding keratinocytes are involved in the melanogenic pathway by stimulating the switch between phaeomelanin and eumelanin [1]. In this pathway, microphthalmia transcription factor (MITF) plays a central role by regulating the expression of the TYR (Tyrosinase), TRP-1 (Tyrosine Related Protein) and DCT (Dopachrome Tautomerase) genes that encode enzymes involved in pigment manufacture $[2,3]$.

Coat colour is highly polymorphic in dogs. In 1957, Little described, after observing the possible phenotypes, more than 20 loci affecting coat colours [4,5]. Until recently, only a few genes were recognised as involved in pigmentation. However, more and more genes, alleles and new interactions are being discovered: variants of melanocortine 1 receptor gene $(M C 1 R)$, (locus previously called extension E) [6-8], variants of Agouti, the antagonist ligand of MC1R [9,10], variants of tyrosinase-related protein 1 (TYRP1) [11] and variants of melanophillin [12]. Three mutations responsible for the brown coat colour versus black coat colour were described in TYRP1 in several dog breeds including the Australian Shepherd dog [11]. Genomic tools are now fully available in canine genetics: dense radiation hybrid maps with 1500 polymorphic microsatellite markers and anchored BAC markers [13,14], a radiation hybrid map comprising 10,000 canine gene-based markers [15], and a whole sequence assembly of the canine genome, build 2.1 [16]. Altogether, the dog appears to be a good model for understanding better the genetics of pigmentation in mammals and for isolating new genes, new variants and interactions between alleles of different loci.

We are interested in the merle phenotype because of its involvement in coat colour and developmental impairments. The merle phenotype is a dominant trait, with heterozygous dogs presenting a coat colour in which eumelanic regions are incompletely and irregularly diluted, leaving intensely pigmented patches. Merle is found throughout the body except on the pheomelanic regions of the black and tan coat colour (Figure 1A, 1B). These dogs often have heterochromia iridis or blue eyes and often have a lack of retinal pigment visible on the fundus. Homozygous merle dogs display a more severe phenotype. The dogs are usually very pale, sometimes completely white and present developmental defects with an incomplete penetrance, microphthalmia and hearing loss (Figure 1C, 1D). In merle European lineages, microphthalmia and/or hearing loss are not frequently observed as breeders avoid mating merle dogs to avoid these developmental defects. However, several veterinary studies on the "merle syndrome", reported retinal defects [17], microphthalmia and coloboma [18]. The non-survival or degeneration of melanocytes in the cochlea have been suggested to explain hearing loss [19].

When analysing the genetic basis of the merle phenotype, Little suggested that a unique locus (called $\mathrm{M}$ ) was responsible for the merle phenotype in different breeds [4]. It was proposed that the merle coat colour may be due to a transposable element, after the observation of two germinal reversions out of 66 merle offspring of a homozygous merle female [20]. Recently, the Kit Ligand, KITLG, was excluded as a candidate gene for the merle phenotype in dogs [21] and the candidate gene approach has not yet give any conclusive results.

We searched for candidate genes for the merle phenotype in dogs by considering well-described pigment disorders in mice. Mutations in the gene of the Mitf pathway cause specific coat colour phenotypes, some of which are similar to the merle phenotype in dogs. These include dilution of the coat colour in patches and complete or mild microphthalmia (Figure 1E, 1F). Also, the complete abolition of functional Mitf results in loss of the melanocyte lineage, causing a white coat colour due to a lack of pigment cell manufacturer, and additional eye (microphthalmia) and inner ear disorders. Heteroallelic combinations of MITF variants produce animals with normal sized dark eyes and yellowish-brown to grey spotted checker board-like coat colours [22,23]. Mitf is also involved in human Waardenburg syndromes, including pigment cell migration disorders [24] and developmental defects such as deafness. Pax3 (Paired box gene 3) and Sox10 (SRY - Sex determining region Y-box 10), which regulates MITF gene expression, are also associated with this syndrome $[25,26]$. This genetic evidence suggest that MITF, PAX3 and SOX10 genes may be candidate genes for the merle phenotype.

We collected a pedigree of Australian shepherd dogs and used a genetic linkage approach with microsatellite markers flanking the MITF, PAX3 and SOX10 candidate genes to search for the genetic bases of the merle coat colour in canines. Although these three genes were excluded for the merle phenotype in dogs, we successfully identified the merle locus on canine chromosome 10, close to the centromere, $20 \mathrm{Mb}$ away from Sox10. This locus was restricted to a $5.5 \mathrm{Mb}$ interval and was further confirmed by analysing families of other breeds segregating the merle phenotype. 

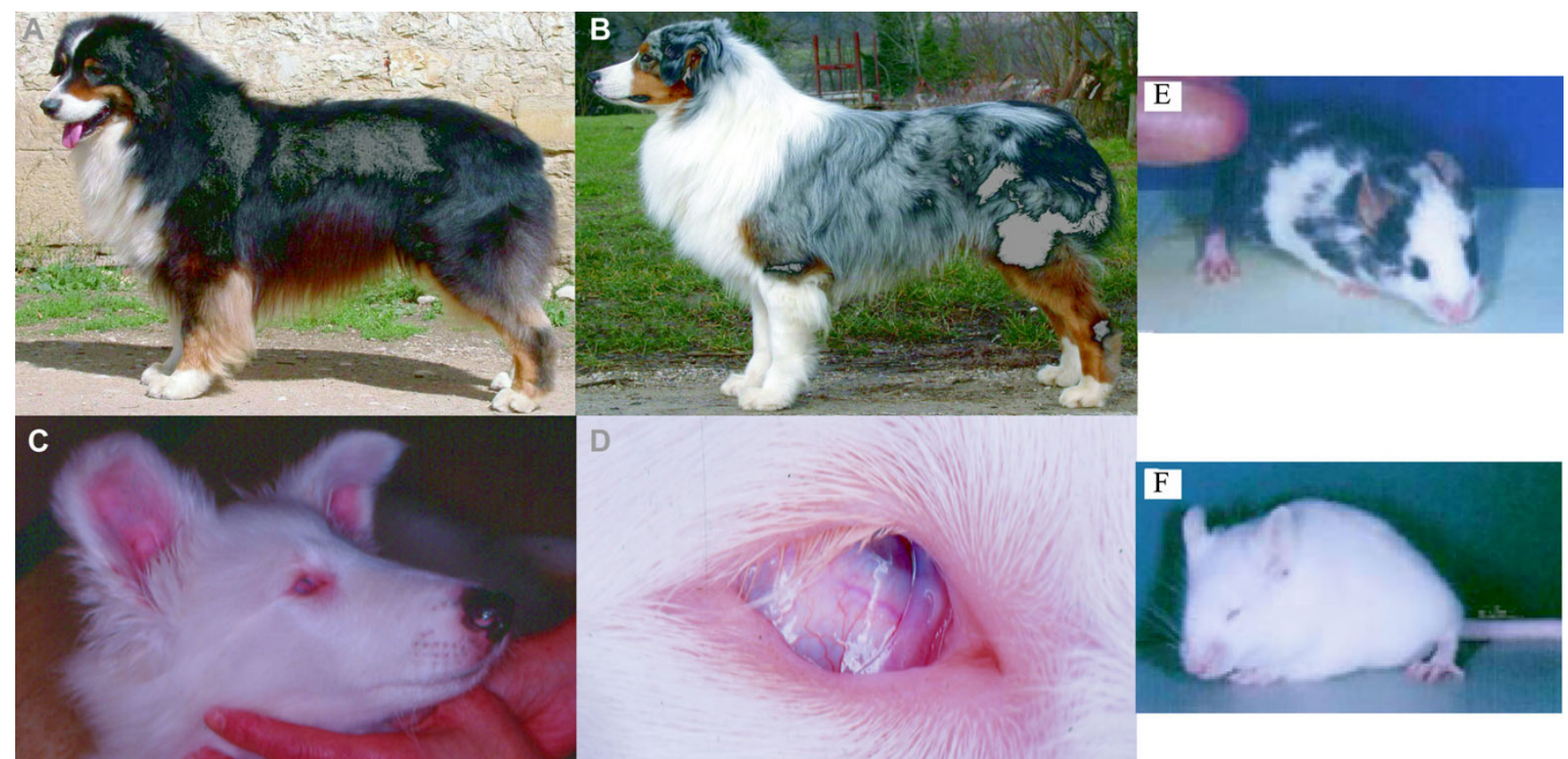

Figure I

Pictures of none merle and merle dogs and mice microphthalmia mutants. A: Black and tan Australian Shepherd dog. B: Heterozygous merle Australian shepherd dog (pictures from Elevage du Paradis Sauvage de Ménestruel, Poncin, France) [40]. C: Six-month homozygous merle collie: the coat colour is totally white and the dog is blind and deaf. D: The left eye of the same dog, shows a microphthalmia with microcornea and a cataract (pictures from Dr Gilles Chaudieu, DVM, Dip. ECVO,

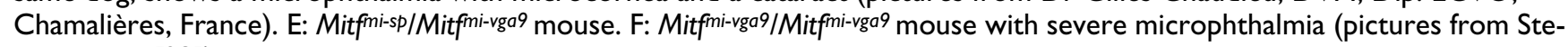
ingrímsson [23]).

\section{Results \\ Pedigrees}

A pedigree comprising 96 Australian shepherd dogs (43 brown and 53 black dogs) was collected. This pedigree, called the "complete pedigree", included 42 merle dogs. A sub-pedigree of 38 dogs, including 17 merle dogs, derived from the complete pedigree was used for genotyping (Figure 2). Isolated families from different breeds segregating the merle coat colour were also collected, including three dachshund families (14 dogs); a Beauce shepherd family (five dogs) and a Border collie family (13 dogs).

\section{Genetic linkage analysis of the brown coat colour in the pedigrees}

We evaluated the linkage power of the pedigrees by investigating the genetic linkage between the brown phenotype and the TYRP1 gene in the complete pedigree. As the TYRP1 gene was previously associated with the brown coat colour in dogs [11], we genotyped markers linked to TYRP1. These markers, FH2319 and REN105I03, are 1.18 and 5.17 Mb from TYRP1, respectively (see Additional file $1)$. The Lod scores between the brown phenotype and FH2319 and REN105I03 markers obtained by a two-point analysis on the complete pedigree, were 7.2 and 3.5 respectively, with a recombination fraction of $\theta=0$. For the sub-pedigree, the Lod scores were 3.6 and 2.4 respectively at $\theta=0$. The number of informative meiosis for the brown phenotype was 58 in the complete pedigree and 16 in the sub-pedigree. As the number of informative meiosis for the merle phenotype significantly increased to 81 and 33 in the complete pedigree and sub-pedigree, respectively, we expected these present pedigrees to be valuable for linkage analysis of the merle phenotype.

\section{Genetic linkage analysis of the merle trait}

As expected, the transmission mode in the collected pedigrees was consistent with an autosomal dominant segregation of the merle phenotype.

Using the sub-pedigree, we carried out genetic linkage analysis on polymorphic markers either flanking or within the intronic part of TYRP1 gene and the candidate genes MITF, PAX3, and SOX 10. Two-point analysis showed no significant linkage between the merle phenotype and markers flanking the MITF and PAX3 genes (Table 1). Therefore, we could exclude MITF and PAX3 being involved in this phenotype. However, we found significant linkages (Lod scores ranging from 3.09 to 3.65) with markers flanking SOX10, with recombination fractions, $\theta$, ranging from 0.08 to 0.14 (Table 2). This sug- 


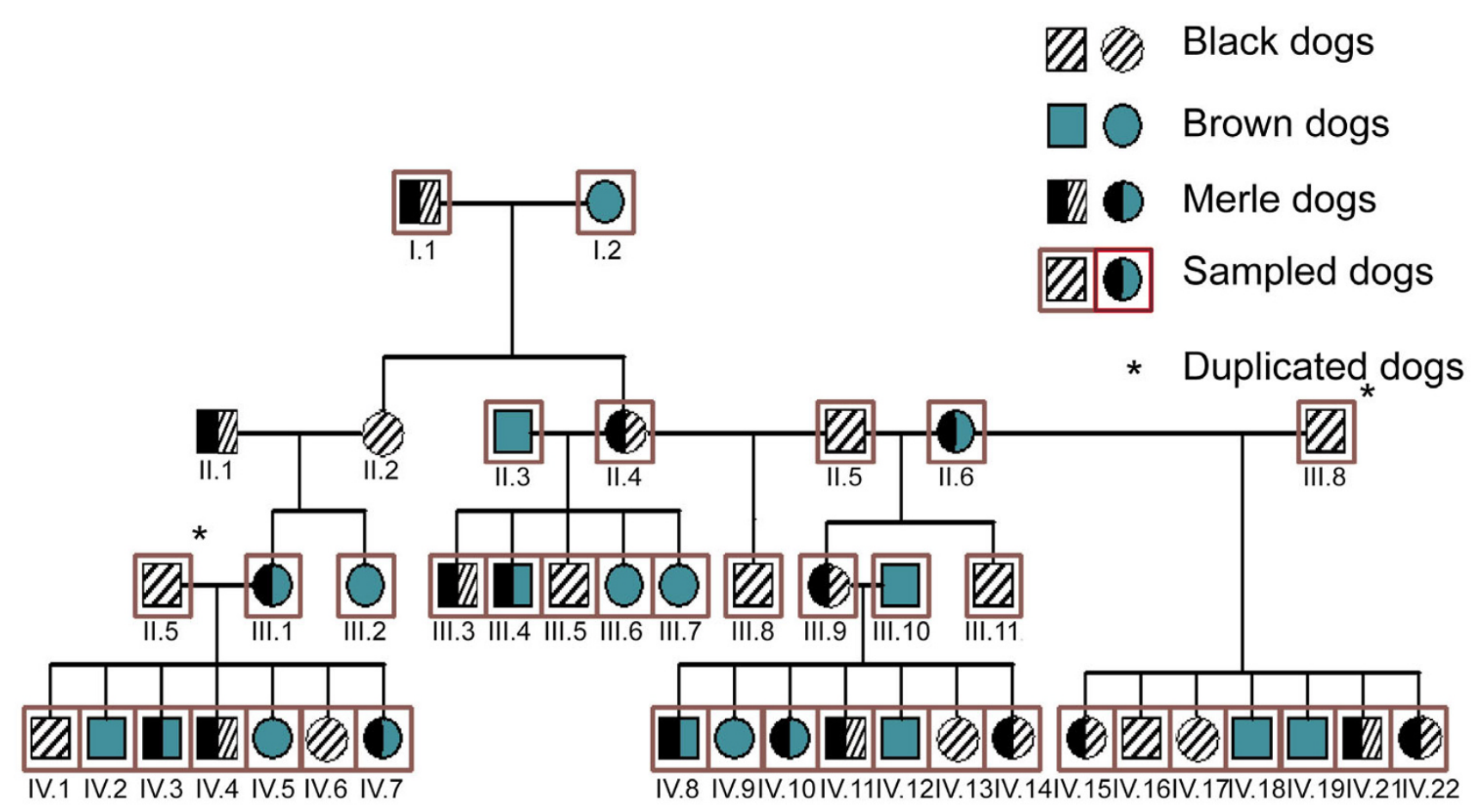

Figure 2

Sub-pedigree of 38 sampled Australian shepherd dogs (19 brown and 19 black dogs).

gested that the merle locus was about $10 \mathrm{cM}$ from SOX10. As part of a "chromosome walking strategy", we selected 30 new polymorphic markers spanning a $27 \mathrm{Mb}$ region from the SOX10 region to the centromeric tip of CFA10, as the C10.769 marker telomeric to SOX10 had a decreasing Lod score (Table 2).

Linkage analysis allowed us to identify seven markers close to the centromere, CFA10.1 to CFA10.8, which cosegregate with the merle phenotype with significant Lod scores (>3) (Table 2, see Additional file 2).

We extended the genetic linkage by analysing the nine most centromeric markers in the "complete pedigree" and in three nuclear families of dachshund, Beauce shepherd and Border collie segregating the merle phenotype. We obtained increased Lod scores for markers CFA10.1 to CFA10.8, with maximum Lod scores for CFA10.7 and CFA10.8 (Lod scores at $\theta=0$ of 15.65 and 14.90 in the complete pedigree and 19.87 and 19.57 in the complete pedigree plus the three other families, respectively). The CFA10.9 marker (telomeric to CFA10.8) is unlinked to the phenotype (Lod scores at $\theta=0$ of -14.38 in the complete pedigree and -11.97 in the complete pedigree plus the three other families, respectively, Table 2). Haplotype analyses of this region allowed us to detect a recombination event between the merle phenotype and the CFA10.9 microsatellite, thus limiting further the merle locus (Figure 3 ). These data, as well as the previous results for SOX10 flanking markers (Table 2), allowed us to exclude the SOX10 gene as being involved in the merle phenotype. Our results show that the merle locus is located in a $5.5 \mathrm{Mb}$ region between the end of the centromere, arbitrarily located at $3 \mathrm{Mb}$, (represented by CFA10.1 located at 3.1 $\mathrm{Mb}$ ) and the CFA10.9 marker (located at 8.5 Mb) defining the telomeric limit of the critical interval (see Additional file 2).

\section{Discussion}

In the present study, we used a genetic linkage approach on a pedigree of Australian shepherd dogs segregating the merle phenotype. We identified with high statistical support a $5.5 \mathrm{Mb}$ locus at the centromeric tip of CFA10 in which the gene responsible for this phenotype should be found. Dog samples were collected from breeders. As phenotyping was easily and immediately detectable after birth by breeders themselves and then officially declared to the breed club, we have been able to obtain an informative family with as many as five generations of Australian shepherd dogs. Moreover, parentage testing ensured good 
Table I: Linkage data between the merle phenotype and markers flanking the TYRPI gene and MITF and PAX3 candidate genes. Two point Lod scores and recombination fractions $(\theta)$ between the merle phenotype and the markers flanking TYRPI, MITF and PAX3 genes calculated on the sub-pedigree. a CFA: Canis familiaris chromosome. b Starred markers were selected from the CanFam I.0 canine sequence draft. Significant exclusions (<-2) are indicated in bold.

\begin{tabular}{|c|c|c|c|c|c|c|c|c|c|c|c|}
\hline \multirow[b]{2}{*}{$\mathrm{CFA}^{\mathrm{a}}$} & \multirow[b]{2}{*}{ Gene/Markers ${ }^{b}$} & \multirow[b]{2}{*}{$\begin{array}{l}\text { Gene/Marker } \\
\text { Position in bp }\end{array}$} & \multicolumn{2}{|c|}{$\theta$ at Lod score $\max$} & \multicolumn{7}{|c|}{ Lod scores at $\theta$} \\
\hline & & & $\theta$ & Lod score max & 0.001 & 0.01 & 0.05 & 0.1 & 0.15 & 0.2 & 0.3 \\
\hline \multirow[t]{6}{*}{ CFAII } & TYRPI & $34,664779-34,683 \mid 48$ & & & & & & & & & \\
\hline & $\mathrm{FH} 2319$ & $35,863893-35,864169$ & 0.5 & 0.0 & -23.083 & -13.146 & -6.442 & -3.802 & -2.429 & -1.582 & -0.661 \\
\hline & Ren 105103 & $39,85776 I-39,857999$ & 0.5 & 0.0 & -15.888 & -8.939 & -4.278 & $-2.47 \mid$ & -1.549 & -0.995 & -0.417 \\
\hline & Ren96j16 & $22,98|53|-22,981669$ & 0.5 & 0.0 & -13.194 & -8.198 & -4.721 & -3.24 & -2.384 & -1.786 & -0.963 \\
\hline & Ren I30E03 & $22,98|5||-22,98| 683$ & 0.5 & 0.0 & -13.194 & -8.198 & -4.721 & -3.24 & -2.384 & -1.786 & -0.963 \\
\hline & Ren I59M20 & $23,456266-23,456464$ & 0.5 & 0.0 & -19.789 & -11.82 & -6.37 & -4.141 & -2.915 & -2.1 & $-|.06|$ \\
\hline \multirow[t]{6}{*}{ CFA20 } & MITF & $24,70|4| 8-24,735483$ & & & & & & & & & \\
\hline & Ren $100 j 13$ & $25,668407-25,668570$ & 0.5 & 0.0 & -24.585 & $-|4.62|$ & -7.791 & -4.988 & -3.442 & -2.417 & -1.131 \\
\hline & Ren I 78E07 & $26,9|| 25|-26,9| 1383$ & 0.5 & 0.0 & -12.593 & -7.605 & -4.164 & -2.729 & -1.923 & -1.377 & -0.671 \\
\hline & Ren $105 M 20$ & $19,606338-19,606486$ & 0.4 & 0.087 & -8.992 & -5.016 & -2.327 & -1.264 & -0.709 & -0.367 & -0.011 \\
\hline & Ren67C18 & $22,36|| 3|-22,36| 265$ & 0.5 & 0.0 & -11.992 & -7.012 & -3.606 & -2.218 & -1.462 & -0.969 & -0.379 \\
\hline & $\operatorname{Pax} 3.2^{*}$ & $30,|85679-30| 8603 \mid$, & 0.27 & 0.147 & -9.89 & -4.957 & -1.763 & -0.644 & -0.159 & 0.063 & 0.137 \\
\hline \multirow[t]{3}{*}{ CFA37 } & PAX3 & $31,332182-31,429995$ & & & & & & & & & \\
\hline & Pax3.1* & $31,368786-31,369020$ & 0.5 & 0.0 & -20.085 & -11.159 & -5.204 & -2.924 & -1.779 & -1.101 & -0.418 \\
\hline & Ren75L05 & $31,649572-31,649607$ & 0.5 & 0.0 & -9.294 & -5.321 & -2.65 & -1.605 & -1.065 & -0.732 & -0.36 \\
\hline
\end{tabular}

reliability of the pedigrees. Such collected pedigrees from existing families means that housing of dogs is not required, limiting housing costs and ethical issues.

We focused on three candidate genes belonging to the coat colour pathway: MITF, PAX3 and SOX 10. The merle phenotype shares similarities with Mitf mouse mutants in coat colour and ocular and hearing defects, and also with human Waardenburg patients. However, our genetic linkage study ruled out these three genes as being involved in the merle phenotype. Genetic analysis of the SOX10 region in the sub-pedigree, using a "chromosome walking" strategy on CFA10, allowed us to identify the merle locus. It spans a $5.5 \mathrm{Mb}$ region $20 \mathrm{Mb}$ away from SOX10. Genetic linkage analyses on the complete pedigree and on small families from other breeds confirmed that the merle locus was located between the CFA10 centromere $(3 \mathrm{Mb})$ and the CFA10.9 marker (8.5 Mb), with the highest Lod score of 19.87 .

The corresponding orthologous human region is HSA12q13-q14 (position from $54.36 \mathrm{Mb}$ to $60.94 \mathrm{Mb}$ ) and mouse region is MMU10D3 (position from $122.8 \mathrm{Mb}$ to $128.7 \mathrm{Mb}$ ). These orthologous dog, human and mouse regions correspond to a unique conserved ordered segment, which has the same orientation in dogs and humans but is inverted between dogs and mice. In the dog region, 99 genes are predicted and 48 are known (Broad1), in the human region, 134 genes are predicted and 98 are known (NCBI 35), and in the mouse region, 112 genes are predicted and 95 are known (NCBI M34) [27]. These gene numbers may vary due to slight changes in the annotated genes as the versions are updated. In humans, mice and dogs, the conserved segments are totally ordered, making annotation of the dog segment easy, thus helping determination of candidate merle genes. This locus has many candidate genes, with at least a dozen being potential metabolic candidates as they, or their paralogs, belong to the pigmentation pathway. These include proteins involved in neural crest development (such as ERBB3), melanosome motility and transfer to surrounding keratinocytes (such as Silv/Pmel-17 and rab, kinesin, dynactin, myosin proteins).

Although the MITF gene itself has been excluded, the merle mutation should affect a gene interacting directly with the MITF gene in the pigmentation pathway. Alternatively, a more complex mechanism could explain the incomplete penetrance of eye defects observed in homozygous merle dogs. Although hearing loss may be due to an extreme white phenotype, including the absence of melanocytes in the cochlea, as in other white canine breeds [28], less is known about the origins of microphthalmia and other ocular defects. These may be due to another mutation in the same locus.

The merle phenotype occurs in several breeds and is commonly encountered in mongrel dogs. Breeds segregating 
Table 2: Linkage data between the merle phenotype and CFA10 markers. List of the CFAI 0 genotyped markers in the sub-pedigree (left), the complete pedigree (middle) and all the studied pedigrees (right), with their two point Lod scores and recombination fractions $(\theta)$. All markers were selected from CanFam I.0 sequence draft except FH2293 and CI0769 taken from Guyon et al.[13]. The markers are ordered in the table from the centromere to the telomere. a markers flanking the SOXIO gene. Values in bold correspond to the highest Lod scores obtained in the three conditions.

Two point Lod scores values

\begin{tabular}{|c|c|c|c|c|c|c|c|c|c|c|c|}
\hline & \multirow[b]{2}{*}{ Gene/Marker names } & \multirow[b]{2}{*}{ Marker Position (in bp) } & \multicolumn{2}{|c|}{$\theta$ at Lod max } & \multicolumn{7}{|c|}{ Lod scores at $\theta$} \\
\hline & & & $\theta$ & Lod max & 0.001 & 0.01 & 0.05 & 0.1 & 0.15 & 0.2 & 0.3 \\
\hline \multirow{41}{*}{$\begin{array}{l}\text { Lod scores in the } \\
\text { sub-pedigree }\end{array}$} & CFAI0.I & $3,109459-3,109703$ & 0.00 & 6.32 & 6.31 & 6.22 & 5.79 & 5.23 & 4.64 & 4.02 & 2.68 \\
\hline & CFAI 0.2 & $3,150322-3,150695$ & 0.00 & 6.92 & 6.91 & 6.82 & 6.37 & 5.78 & 5.16 & 4.50 & 3.05 \\
\hline & CFAI 0.3 & $3,169429-3,169640$ & 0.00 & 3.01 & 3.01 & 2.95 & 2.72 & 2.42 & 2.10 & 1.76 & 1.06 \\
\hline & CFAI 0.4 & $3,45245 \mathrm{I}-3,452757$ & 0.04 & 5.94 & 4.82 & 5.71 & 5.90 & 5.55 & 5.04 & 4.44 & 3.04 \\
\hline & CFAI $0.5^{c}$ & $3,533969-3,534312$ & 0.00 & 6.92 & 6.91 & 6.81 & 6.35 & 5.73 & 5.09 & 4.40 & 2.90 \\
\hline & CFAI0.6 & $4,050670-4,050915$ & 0.00 & 3.01 & 3.01 & 2.96 & 2.74 & 2.46 & 2.17 & 1.86 & 1.20 \\
\hline & CFAI 0.7 & $4,901919-4,902276$ & 0.00 & 7.23 & 7.21 & 7.11 & 6.65 & 6.04 & 5.39 & 4.71 & 3.20 \\
\hline & CFAI 0.8 & $6,938580-6,938928$ & 0.00 & 7.23 & 7.21 & 7.11 & 6.65 & 6.04 & 5.39 & 4.71 & 3.20 \\
\hline & CFAI0.9 & $8,539383-8,539710$ & 0.50 & 0.00 & -20.08 & -11.15 & -5.16 & -2.85 & -1.68 & -0.98 & -0.31 \\
\hline & CFAI0.10 & $9,459108-9,459324$ & 0.07 & 2.62 & 1.21 & 2.15 & 2.60 & 2.57 & 2.40 & 2.16 & 1.52 \\
\hline & CFAI0.II & $10,599594-10,599989$ & 0.04 & 5.08 & 3.91 & 4.82 & 5.07 & 4.79 & 4.35 & 3.84 & 2.64 \\
\hline & CFA 10.12 & $12,963916-12,964094$ & 0.15 & 2.55 & -4.49 & -0.58 & 1.79 & 2.43 & 2.55 & 2.44 & 1.83 \\
\hline & CFAI0.13 & $13,290922-13,29 \mid 305$ & 0.18 & 0.75 & -2.99 & -1.03 & 0.21 & 0.60 & 0.73 & 0.74 & 0.57 \\
\hline & CFAI0.14 & $13,687824-13,688059$ & 0.11 & 3.44 & -1.49 & 1.42 & 3.09 & 3.43 & 3.36 & 3.10 & 2.25 \\
\hline & CFAI0.15 & $|5,2875| 3-15,287805$ & 0.14 & 2.22 & -2.99 & -0.06 & 1.69 & 2.15 & 2.21 & 2.08 & 1.51 \\
\hline & CFAI0.16 & $16,325750-16,325992$ & 0.09 & 3.67 & 0.61 & 2.53 & 3.55 & 3.66 & 3.49 & 3.19 & 2.33 \\
\hline & CFA 10.17 & $16,883 \mid 88-16,883575$ & 0.12 & 2.95 & -2.09 & 0.83 & 2.53 & 2.92 & 2.91 & 2.72 & 2.02 \\
\hline & CFAI0.18 & $|7,574| 78-17,574420$ & 0.08 & 3.87 & 0.91 & 2.82 & 3.79 & 3.84 & 3.61 & 3.25 & 2.31 \\
\hline & CFAI0.19 & $18,220318-18,220600$ & 0.10 & 4.20 & -0.58 & 2.31 & 3.93 & 4.20 & 4.07 & 3.74 & 2.75 \\
\hline & CFA 10.20 & $19,075239-19,075433$ & 0.12 & 3.19 & -1.79 & 1.12 & 2.81 & 3.17 & 3.13 & 2.90 & 2.10 \\
\hline & CFAI0.2I & $|9,9990||-| 9,99923 \mid$ & 0.26 & 0.51 & -11.69 & -5.76 & -1.88 & -0.50 & 0.12 & $0.4 I$ & 0.47 \\
\hline & CFAI 0.22 & $21,607022-21,607316$ & 0.10 & 4.45 & -0.28 & 2.61 & 4.20 & 4.45 & 4.30 & 3.95 & 2.90 \\
\hline & CFAI 0.23 & $21,95604 I-21,956337$ & 0.10 & 4.45 & -0.28 & 2.61 & 4.20 & 4.45 & 4.30 & 3.95 & 2.90 \\
\hline & CFAI 0.24 & $23,1 \mid 3457-23,113656$ & 0.25 & 0.92 & -13.18 & -6.27 & -1.77 & -0.17 & 0.52 & 0.83 & 0.85 \\
\hline & CFAI 0.25 & $24,03 \mid 569-24,031859$ & 0.10 & 3.51 & -1.19 & 1.70 & 3.28 & 3.51 & 3.34 & 2.97 & 1.93 \\
\hline & CFAI0.26 & $25,504535-25,504764$ & 0.14 & 2.73 & -4.19 & -0.29 & 2.05 & 2.65 & 2.73 & 2.57 & 1.89 \\
\hline & CFAI 0.27 & $25,930447-25,930692$ & 0.12 & 1.84 & -1.49 & 0.45 & 1.58 & 1.83 & 1.81 & 1.67 & 1.16 \\
\hline & CFA 10.28 & $26,491052-26,491288$ & 0.13 & 1.66 & -1.79 & 0.16 & 1.32 & 1.62 & 1.65 & 1.56 & 1.16 \\
\hline & CFAI0.29 & $27,391154-27,391817$ & 0.18 & 2.36 & -6.88 & -1.98 & 1.09 & 2.04 & 2.33 & 2.33 & 1.87 \\
\hline & CFAI 0.30 & $28,230039-28,230419$ & 0.30 & 0.69 & -18.28 & -9.37 & -3.47 & -1.27 & -0.23 & 0.33 & 0.69 \\
\hline & CFAI $0.3 \mathrm{I}^{\mathrm{a}}$ & $29,232270-29,2325 \mathrm{II}$ & 0.13 & 3.51 & -3.28 & 0.61 & 2.90 & 3.46 & 3.49 & 3.27 & 2.45 \\
\hline & CFAI $0.32^{a}$ & $29,355913-29,355989$ & 0.14 & 3.09 & -3.88 & 0.02 & 2.37 & 2.99 & 3.08 & 2.94 & 2.24 \\
\hline & CFAI0.33a & $29,483066-29,483109$ & 0.13 & 2.40 & -2.69 & 0.23 & 1.95 & 2.37 & 2.38 & 2.22 & 1.58 \\
\hline & CFAI $0.34^{\mathrm{a}}$ & $29,826073-29,826290$ & 0.14 & 2.52 & -2.69 & 0.24 & 2.00 & 2.45 & 2.51 & 2.38 & 1.81 \\
\hline & CFAI $0.35^{a}$ & $29,83444 I-29,834690$ & 0.16 & 2.74 & -6.28 & -1.39 & 1.63 & 2.51 & 2.73 & 2.67 & 2.08 \\
\hline & sox 10 & $29,856920-29,867728$ & & & & & & & & & \\
\hline & CFAI $0.36^{a}$ & $29,861299-29,86 \mid 547$ & 0.08 & 3.60 & 0.61 & 2.52 & 3.51 & 3.58 & 3.37 & 3.02 & 2.10 \\
\hline & CFAI0.37a & $29,868038-29,868267$ & 0.14 & 3.38 & -3.58 & 0.32 & 2.67 & 3.29 & 3.37 & 3.21 & 2.47 \\
\hline & CFA $10.38^{a}$ & $30,176995-30,177378$ & 0.11 & 3.65 & -1.19 & 1.71 & 3.35 & 3.65 & 3.55 & 3.26 & 2.38 \\
\hline & $\mathrm{FH} 2293^{\mathrm{a}}$ & $31,696028-31,696274$ & 0.13 & 3.56 & -3.28 & 0.61 & 2.93 & 3.50 & 3.54 & 3.34 & 2.53 \\
\hline & CI0.769a & $36,663349-36,663563$ & 0.18 & 1.50 & -5.99 & -2.06 & 0.42 & 1.20 & 1.46 & 1.49 & 1.18 \\
\hline \multirow{8}{*}{$\begin{array}{l}\text { Lod scores in the } \\
\text { complete pedigree }\end{array}$} & CFAI0.I & $3,109459-3,109703$ & 0.00 & 11.74 & 11.72 & 11.54 & 10.70 & 9.61 & 8.46 & 7.27 & 4.71 \\
\hline & CFAI 0.2 & $3,150322-3,150695$ & 0.02 & 11.97 & 11.13 & 11.91 & 11.63 & 10.64 & 9.48 & 8.20 & 5.38 \\
\hline & CFAI 0.3 & $3,169429-3,169640$ & 0.00 & 6.62 & 6.61 & 6.50 & 5.98 & 5.30 & 4.60 & 3.86 & 2.33 \\
\hline & CFAI 0.4 & $3,45245 \mathrm{I}-3,452757$ & 0.03 & 13.82 & 11.73 & 13.46 & 13.65 & 12.67 & 11.36 & 9.88 & 6.55 \\
\hline & CFAI0.5 c & $3,533969-3,534312$ & 0.02 & 8.77 & 7.82 & 8.65 & 8.58 & 7.88 & 7.01 & 6.03 & 3.86 \\
\hline & CFAI 0.6 & $4,050670-4,050915$ & 0.00 & 6.92 & 6.91 & 6.79 & 6.24 & 5.51 & 4.76 & 3.99 & 2.41 \\
\hline & CFAI0.7 & $4,901919-4,902276$ & 0.00 & 15.65 & 15.63 & 15.39 & 14.30 & 12.88 & $1 \mathrm{I} .40$ & 9.84 & 6.54 \\
\hline & CFAI 0.8 & $6,938580-6,938928$ & 0.02 & 14.90 & 14.13 & 14.87 & 14.39 & 13.16 & 11.72 & 10.17 & 6.76 \\
\hline
\end{tabular}


Table 2: Linkage data between the merle phenotype and CFAI 0 markers. List of the CFA 10 genotyped markers in the sub-pedigree (left), the complete pedigree (middle) and all the studied pedigrees (right), with their two point Lod scores and recombination fractions $(\theta)$. All markers were selected from CanFam I.0 sequence draft except FH2293 and CI0769 taken from Guyon et al.[13]. The markers are ordered in the table from the centromere to the telomere. a markers flanking the SOX 10 gene. Values in bold correspond to the highest Lod scores obtained in the three conditions. (Continued)

\begin{tabular}{|c|c|c|c|c|c|c|c|c|c|c|c|}
\hline & CFAI 0.9 & $8,539383-8,539710$ & 0.19 & 2.48 & -14.38 & -5.54 & 0.02 & 1.78 & 2.38 & 2.47 & 1.89 \\
\hline \multirow{9}{*}{$\begin{array}{l}\text { Lod scores in the } \\
\text { complete pedigree } \\
\text { plus families } \\
\text { of dachshund, } \\
\text { Beauce shepherd } \\
\text { and Border collie }\end{array}$} & CFAI0.I & $3,109459-3,109703$ & 0.04 & 10.67 & 8.43 & 10.21 & 10.61 & 9.91 & 8.91 & 7.74 & 5.09 \\
\hline & CFAI0.2 & $3,150322-3,150695$ & 0.04 & 10.97 & 8.73 & $10.5 \mid$ & 10.91 & 10.21 & 9.21 & 8.04 & 5.39 \\
\hline & CFAI 0.3 & $3,169429-3,169640$ & 0.00 & 6.02 & 6.01 & 5.91 & 5.44 & 4.84 & 4.22 & 3.56 & 2.20 \\
\hline & CFAI 0.4 & $3,45245 \mathrm{I}-3,452757$ & 0.03 & 14.38 & 12.33 & 14.05 & 14.19 & 13.15 & 11.79 & 10.25 & 6.83 \\
\hline & CFAI0.5 c & $3,533969-3,534312$ & 0.02 & 8.77 & 7.82 & 8.65 & 8.58 & 7.89 & 7.02 & 6.05 & 3.90 \\
\hline & CFAI0.6 & $4,050670-4,050915$ & 0.03 & 6.99 & 6.01 & 6.86 & 6.85 & 6.23 & 5.46 & 4.61 & 2.82 \\
\hline & CFAI 0.7 & $4,901919-4,902276$ & 0.00 & 19.87 & 19.83 & 19.52 & 18.11 & 16.28 & 14.37 & 12.37 & 8.15 \\
\hline & CFAI 0.8 & $6,938580-6,938928$ & 0.00 & 19.57 & 19.53 & 19.22 & 17.82 & 15.99 & 14.08 & 12.09 & 7.91 \\
\hline & CFAI 0.9 & $8,539383-8,539710$ & 0.16 & 4.23 & -11.97 & -3.16 & 2.25 & 3.83 & 4.22 & 4.10 & 3.02 \\
\hline
\end{tabular}

merle are from the collie lineage (Group 1-FCI - Federation Cynologique Internationale classification): Shetland sheepdog, Border collie, collie, Australian shepherd dog, etc., and from other unrelated breeds belonging to different FCI groups and different clusters, as defined by Parker et al. [29], such as dachshund (Group 4-FCI):, Beauce shepherd (Group 1-FCI), great Dane (Group 2-FCI), Welsh corgi cardigan and Pyrenean shepherd. The merle phenotype is most probably very old, with the merle coat colour being reported in old books [30,31], from which drawings of merle dogs have been selected and reproduced [32].

It is not yet known whether the genetic cause of the merle phenotype is the same in all breeds and mongrels segregating this phenotype. A unique locus has been suggested as responsible for the merle coat colour [4]. In the present study, the increased Lod scores observed for genotyped markers from the merle locus in dachshund, Beauce shepherd and Border collie families is consistent, at least in these breeds, with there being a unique locus for the merle coat colour. If all merle dogs share a common ancestor chromosome, all breeds segregating merle could be used to refine the locus. The sharing of the merle locus by several breeds and also by mongrels may be due either to a common ancestor chromosome region being transmitted throughout canine evolution and/or to backcrosses that introduced a merle haplotype in several breeds at different times.

\section{Conclusion}

Using genetic linkage analysis, we excluded the involvement of the MITF, PAX3 and SOX 10 candidates genes in the merle phenotype. However, we identified the merle locus at the centromeric end of CFA10 in pedigrees of Australian shepherd dogs, dachshund, Beauce shepherd dogs and Border collies segregating the merle phenotype. This locus spans $5.5 \mathrm{Mb}$ and is linked to the merle coat colour with a maximum Lod score of 19.87 and a recombination fraction of 0 . We are currently analysing this locus in several breeds segregating merle, with a high density of single nucleotide polymorphic markers (SNP). This should help in identifying the merle gene. As well as benefiting breeding practices and canine veterinary medicine, identifying the merle gene will also help in understanding the genetic bases of mammalian pigmentation and developmental pathways.

\section{Methods}

\section{Genomic DNA extraction}

No dogs were housed for research purposes, and all dogs were privately owned pets.

Blood samples and the accompanying pedigree and coat colour data (with pictures when possible) were collected by DVM veterinarians. All data were entered into a database. Genomic DNA was extracted from $5 \mathrm{ml}$ of blood collected on EDTA, using the nucleon BACC 3 kit (Amersham Biosciences, Piscataway, NJ, USA). For low concentration samples, the extracted DNA was "whole genome amplified" using the genomiphi kit (Amersham Biosciences).

\section{Canine pedigree}

Pedigrees were constructed using the Cyrillic software (Cyrillic2.1) [33], which allows haplotypes from the genotyping data to be drawn and the data to be exported in different formats for use in genetic linkage analysis. We carried out genotyping of 20 polymorphic microsatellites from four different chromosomes (CFA10, 11, 20 and 37) to check and validate the parentage compatibility.

\section{Markers selection and Genotyping experiments}

Microsatellite markers were selected from RH map data $[13,34]$ or from the CanFam $1.0 \mathrm{draft}$ of the canine genome sequence [35]. Markers were selected from their 


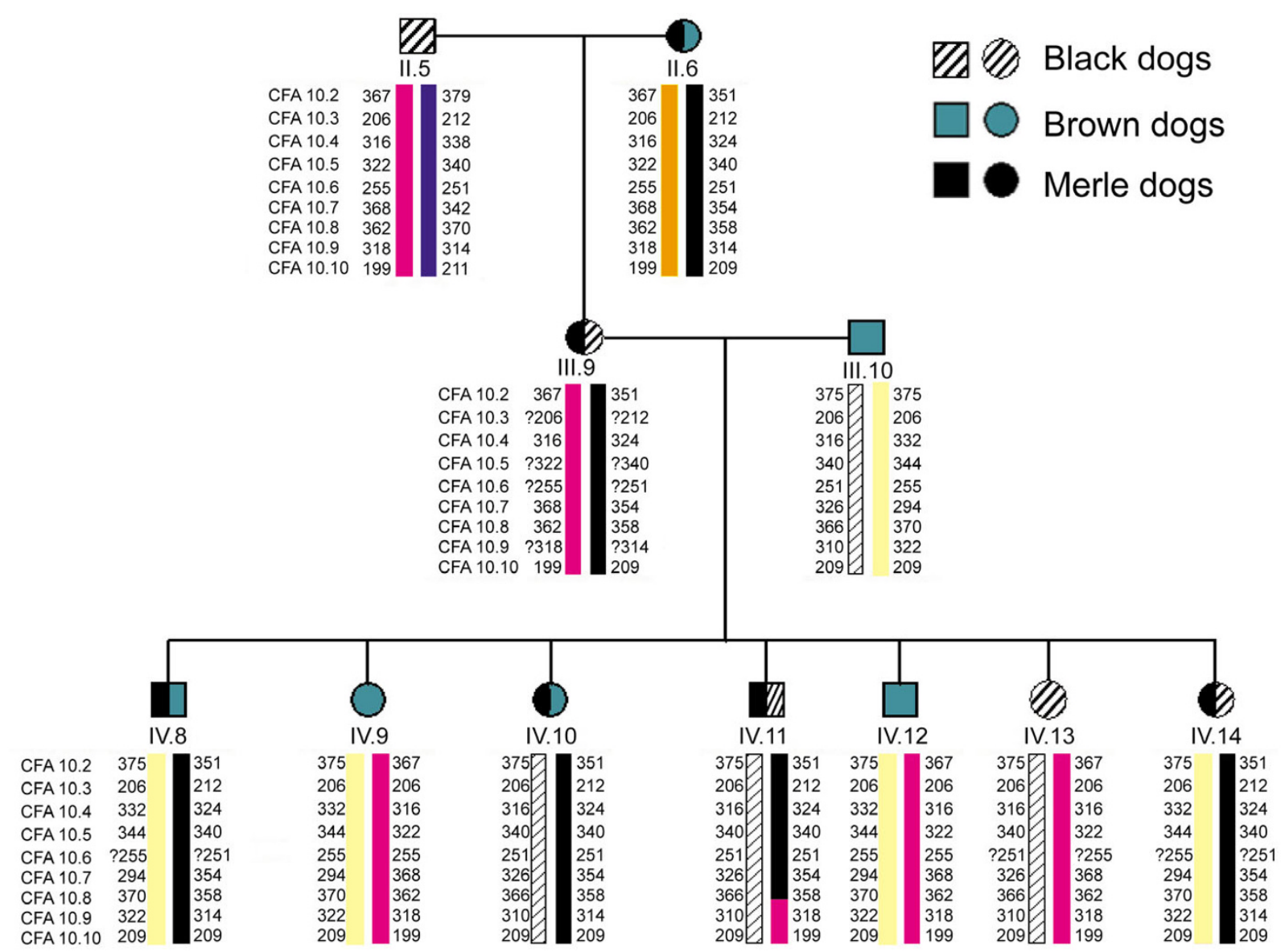

Figure 3

Haplotype analysis of the centromeric end of CFA I 0. Analysis revealed a crossing-over between CFA I0.8 and CFAI0.9 markers (dog IV.I I), limiting the merle locus in between the centromeric end and the CFAI0.9 marker. The merle chromosome is shown in black. Alleles with a question mark indicate that the parental origin of the allele could not be determined.

position and their polymorphism level (see Additional file 1). We used Primer3 software to design PCR primers [36].

Microsatellite markers were labelled using a two-step-PCR fluorescent labelling procedure [37]. The first step was carried out on $50 \mathrm{ng}$ of dog genomic DNA using a classical PCR protocol and a touchdown program of $61^{\circ} \mathrm{C}$ to $51^{\circ} \mathrm{C}$. The second step consisted of a one strand labelling PCR as previously described [37]. The PCR products were purified using Sephadex G50 fine column filtration in a 96 format (Amersham Biosciences). An aliquot of $3 \mu \mathrm{l} \mathrm{flu-}$ orescent purified PCR product was mixed with $0.3 \mu \mathrm{l}(0.2$ $\mathrm{nM}$ ) of fluorescent geneScan-500 ROX size standard (Applied Biosystems) and $8.7 \mu$ l of formamide, and then loaded onto a 3130 XL genetic analyser (Applied Biosystems). Results were analysed using GeneMapper software v3.7 (Applied Biosystems) and the genotyping data were used by Cyrillic software for the genetic linkage analysis.

\section{Genetic linkage analysis}

Haplotypes were constructed using the Cyrillic software. Two-point linkage analysis was carried out between each marker and the merle phenotype using M-LINK software through the GLUE web interface [38] and MultiMap software [39]. We used the 'prepare' option of CRI-MAP to check for Mendelian segregation. The linkage between each pair of markers was carried out with the TWOPOINT option of CRI-MAP. Lod scores were calculated assuming an autosomal dominant transmission with full penetrance and affected individuals were scored as heterozygous at the phenotype locus.

\section{Authors' contributions}

$\mathrm{BH}$ collected samples, constructed the pedigrees and performed genotyping experiments; $\mathrm{BH}$ also interpreted all dataand actively participated in writing the manuscript. SC helped with the genotyping experiments and interpretation of the dataand participated in writing the manu- 
script. CH carried out the statistical analyses and data interpretation, and critically revised the manuscript. SD helped with the genotyping experiments. TV extracted DNA from blood samples and commented critically on the work and manuscript. TD carried out the synteny analyses. BD contributed with knowledge on canines coat colours and critically revised the manuscript. FG provided intellectual input and critically revised the manuscript. MDG helped conceive and design the work and helped in the writing of the manuscript. CA conceived and designed the work and drafted the manuscript. All authors read and approved the final manuscript.

\section{Additional material}

\section{Additional File 1}

Characteristics of the markers used in the genetic linkage studies. ${ }^{a}$ CFA : Canis familiaris chromosome. ${ }^{b}$ Starred markers were selected from the CanFam 1.0 canine sequence draft, ${ }^{c}$ marker corresponding to marker FH2537 from Guyon et al. [13], ' number of alleles as determined from the sub-pedigree. ${ }^{E}$ Markers flanking SOX10 gene.

Click here for file

[http://www.biomedcentral.com/content/supplementary/17466148-2-9-S1.doc]

\section{Additional File 2}

Scheme of two-point linkage analysis of the merle phenotype in the Australian Shepherd dog pedigrees on CFA10. Two-point linkage analysis of the merle phenotype in the Australian shepherd dog sub-pedigree (in black) and complete pedigree (in brown) (Lod scores at theta $=0$ ) is shown on the right. An ordered list of genotyped markers (right) and genes (left) and their position in $\mathrm{Mb}$ are indicated in the middle. An ideogram of the canine chromosome 10 is shown on the left with the corresponding human chromosomal conserved segments. NB: genomic sequence systematically starts at an arbitrary coordinate of $3 \mathrm{Mb}$ to include the nonsequenced centromeric region.

Click here for file

[http://www.biomedcentral.com/content/supplementary/17466148-2-9-S2.jpeg]

\section{Acknowledgements}

We gratefully acknowledge the CNRS, the Conseil Regional de Bretagne for their financial support, as well as Australian shepherd breeders, (especially Mme Boutarfa and Mme Coosemans, Elevage du Paradis Sauvage de Ménestruel, Poncin, France; Mme Bernard, Elevage de l'Orée des Charmois, Bois Le Roi, France), Mme Rougé, Elevage des Corsaires de Feu, Britany, France and Dr. Gilles Chaudieu, DVM and Dr. Philippe Pilorge, DVM for sampling and pictures.

\section{References}

I. Imokawa G: Autocrine and paracrine regulation of melanocytes in human skin and in pigmentary disorders. Pigment Cell Res 2004, I 7:96-1 I0.

2. Busca R, Ballotti R: Cyclic AMP a key messenger in the regulation of skin pigmentation. Pigment Cell Res 2000, I3:60-69.

3. Widlund HR, Fisher DE: Microphthalamia-associated transcription factor: a critical regulator of pigment cell development and survival. Oncogene 2003, 22:3035-304I.
4. Little CC: The inheritance of coat color in dogs. Edited by: Press CU. Ithaca, NY, ; 1957.

5. Sponenberg DP, Rothschild MF: Genetics of coat colour and hair texture. In The Genetics of the Dog Ruvinsky A , Sampson J edition. New York, NY, CABI Publishing; 2001:61 -685.

6. Everts RE, Rothuizen J, van Oost BA: Identification of a premature stop codon in the melanocyte-stimulating hormone receptor gene (MCIR) in Labrador and Golden retrievers with yellow coat colour. Anim Genet 2000, 3 I:194-199.

7. Newton JM, Wilkie AL, He L, Jordan SA, Metallinos DL, Holmes NG, Jackson IJ, Barsh GS: Melanocortin I receptor variation in the domestic dog. Mamm Genome 2000, I I:24-30.

8. Schmutz SM, Berryere TG, Ellinwood NM, Kerns JA, Barsh GS: MCIR studies in dogs with melanistic mask or brindle patterns. J Hered 2003, 94:69-73.

9. Berryere TG, Kerns JA, Barsh GS, Schmutz SM: Association of an Agouti allele with fawn or sable coat color in domestic dogs. Mamm Genome 2005, 16:262-272.

10. Kerns JA, Newton J, Berryere TG, Rubin EM, Cheng JF, Schmutz SM, Barsh GS: Characterization of the dog Agouti gene and a nonagoutimutation in German Shepherd Dogs. Mamm Genome 2004, 15:798-808.

II. Schmutz SM, Berryere TG, Goldfinch AD: TYRPI and MCIR genotypes and their effects on coat color in dogs. Mamm Genome 2002, 13:380-387.

12. Philipp U, Hamann H, Mecklenburg L, Nishino S, Mignot E, GunzelApel AR, Schmutz SM, Leeb T: Polymorphisms within the canine MLPH gene are associated with dilute coat color in dogs. BMC Genet 2005, 6:34.

13. Guyon R, Lorentzen TD, Hitte C, Kim L, Cadieu E, Parker HG, Quignon $P$, Lowe JK, Renier C, Gelfenbeyn B, Vignaux F, DeFrance HB, Gloux S, Mahairas GG, Andre C, Galibert F, Ostrander EA: A I-Mb resolution radiation hybrid map of the canine genome. Proc Natl Acad Sci U S A 2003, 100:5296-530I.

14. Breen M, Hitte C, Lorentzen TD, Thomas R, Cadieu E, Sabacan L, Scott A, Evanno G, Parker HG, Kirkness EF, Hudson R, Guyon R, Mahairas GG, Gelfenbeyn B, Fraser CM, Andre C, Galibert F, Ostrander EA: An integrated 4249 marker FISH/RH map of the canine genome. BMC Genomics 2004, 5:65.

15. Hitte C, Madeoy J, Kirkness EF, Priat C, Lorentzen TD, Senger F, Thomas D, Derrien T, Ramirez C, Scott C, Evanno G, Pullar B, Cadieu E, Oza V, Lourgant K, Jaffe DB, Tacher S, Dreano S, Berkova N, Andre C. Deloukas P. Fraser C, Lindblad-Toh K, Ostrander EA, Galibert F: Facilitating genome navigation: survey sequencing and dense radiation-hybrid gene mapping. Nat Rev Genet 2005, 6:643-648.

16. Lindblad-Toh K, Wade CM, Mikkelsen TS, Karlsson EK, Jaffe DB, Kamal M, Clamp M, Chang JL, Kulkobas EJ 3rd, Zody MC, et al.: Genome sequence, comparative analysis and haplotype structure of the domestic dog. Nature 2005, 438:803-19.

17. Akcan $A$, Wegner $W$ : Changes in the visual pathways and visual centers in Merle syndrome in the dog. Z Versuchstierkd 1983, 25:91-99.

18. Gelatt KN, Powell NG, Huston K: Inheritance of microphthalmia with coloboma in the Australian shepherd dog. Am J Vet Res I98I, 42:1686-1690.

19. Strain GM: Congenital deafness and its recognition. Vet Clin North Am Small Anim Pract 1999, 29:895-907, vi.

20. Sponenberg DP: Germinal reversion of the merle allele in Australian shepherd dogs. J Hered 1984, 75:78.

21. Schmutz SM, Berryere TG, Sharp CA: KITLG maps to canine chromosome 15 and is excluded as a candidate gene for merle in dogs. Anim Genet 2003, 34:75-76.

22. Hansdottir AG, Palsdottir K, Favor J, Neuhauser-Klaus A, Fuchs H, de Angelis $\mathrm{MH}$, Steingrimsson $\mathrm{E}$ : The novel mouse microphthalmia mutations Mitfmi-enu5 and Mitfmi-bcc2 produce dominant negative Mitf proteins. Genomics 2004, 83:932-935.

23. Steingrimsson E, Arnheiter H, Hallsson JH, Lamoreux ML, Copeland NG, Jenkins NA: Interallelic complementation at the mouse Mitf locus. Genetics 2003, 163:267-276.

24. Tassabehji M, Newton VE, Read AP: Waardenburg syndrome type 2 caused by mutations in the human microphthalmia (MITF) gene. Nat Genet 1994, 8:25I-255.

25. Potterf SB, Furumura M, Dunn KJ, Arnheiter H, Pavan WJ: Transcription factor hierarchy in Waardenburg syndrome: regu- 
lation of MITF expression by SOX 10 and PAX3. Hum Genet 2000, 107:I-6.

26. Watanabe A, Takeda K, Ploplis B, Tachibana M: Epistatic relationship between Waardenburg syndrome genes MITF and PAX3. Nat Genet 1998, 18:283-286.

27. Ensembl: . [http://www.ensembl.org/index.html].

28. Strain GM: Deafness prevalence and pigmentation and gender associations in dog breeds at risk. Vet J 2004, 167:23-32.

29. Parker HG, Kim LV, Sutter NB, Carlson S, Lorentzen TD, Malek TB, Johnson GS, DeFrance HB, Ostrander EA, Kruglyak L: Genetic structure of the purebred domestic dog. Science 2004, 304: II60-II64.

30. Brehm AE: La vie des animaux illustrée. Edited by: Bailleres JB. Paris, ; 1868.

31. Buffon D: Origine des espèces. Volume 3. Edited by: Bureau-de-lasociété-des-Publications-illustrées. Paris, ; 1839.

32. Société-Française-de-Cynotechnie: Nos chiens d'antan. Edited by: Maradi . France, ; 1994.

33. Cyrillic: . [http://www.cyrillicsoftware.com].

34. Canine-Hybrid-Radiation-project: . UMR 606I [http://www-recom gen.univ-rennes l.fr/doggy.html].

35. UCSC: . [http://genome.ucsc.edu].

36. Primer3: . [http://frodo.wi.mit.edu/cgi-bin/primer3/ primer3 www.cgi].

37. Jouquand $S$, Cheron A, Galibert F: Microsatellite analysis using a two-step procedure for fluorescence labeling of PCR products. Biotechniques 1999, 26:902-905.

38. Glue: . [http://menu.hgmp.mrc.ac.uk/menu-bin/GLUE/glue.pl].

39. Matise TC, Perlin M, Chakravarti A: Automated construction of genetic linkage maps using an expert system (MultiMap): a human genome linkage map. Nat Genet 1994, 6:384-390.

40. Elevage-Menestruel: . [http://menestruel.free.fr].

Publish with Bio Med Central and every scientist can read your work free of charge

"BioMed Central will be the most significant development for disseminating the results of biomedical research in our lifetime. "

Sir Paul Nurse, Cancer Research UK

Your research papers will be:

- available free of charge to the entire biomedical community

- peer reviewed and published immediately upon acceptance

- cited in PubMed and archived on PubMed Central

- yours - you keep the copyright

Submit your manuscript here:

http://www.biomedcentral.com/info/publishing_adv.asp 